\title{
Pengaruh Pengalaman Auditor, Time Budget Pressure dan Ukuran Kantor Akuntan Publik Terhadap Audit Report LAG Pada Auditor Kantor Akuntan Publik Di Kota Surabaya
}

\author{
Dewi Sutjahyani \\ Fakultas Ekonomi dan Bisnis Universitas 17 Agustus 1945 Surabaya \\ Correspondence email: dewisutjahyani@untag-sby.ac.id
}

\begin{abstract}
The job of the auditor is to provide useful information, therefore when the audited report is delayed it will reduce the use value of the financial statements presented. Therefore, it is important to identify and have a deeper look at several factors related to the occurrence of audit report lag. Thus, it is necessary to study whether these factors significantly influence the audit report lag. This is important because the audit report lag phenomenon can reduce client interest and affect the reputation of auditors and public accounting firms where auditors work. Hypothesis 1 in this study is rejected, this means that the experience of auditors does not significantly affect the Audit Report Tag. work and the number of inspection tasks. The experience variable does not have a significant effect because audit quality is not determined by the length of work and the number of audit tasks. Hypothesis 2, namely that time budget pressure has an effect on audit report lag, is rejected. Time budget pressure is vital in the process of completing an audit report. In this case the time budget pressure does not have a significant effect because the budget pressure is determined when planning to determine the audit task but the implementation of the audit can be different influenced by the existing situation. For example during a pandemic, uncontrollable situations lead to leeway in the completion of audited reports. So that the existing time budget pressure must be adjusted. The hypothesis in this study is accepted, this is because the size of KAP basically determines the level of efficiency and effectiveness of each auditor's task. In medium and large KAPs, there is usually a structured system and maturity from the audit planning process to the audit. This is because large public accounting firms usually try to maintain quality and reputation to keep their clients interested
\end{abstract}

Keywords: Auditor, Time Budget Pressure, Public Accounting Firm Size, Audit Report Lag

\section{PENDAHULUAN}

Laporan keuangan merupakan media komunikasi antara manjemen dan pihak luar perusahaan. Dengan demikian laporan keuangan merupakan salah satu sumber informasi yang digunakan dalam pengambilan keputusan. Karakteristik kualitatif laporan keuangan menurut IAI adalah: dapat dipahami, relevan, reliabel dan dapat diperbandingkan. Dalam hal ini laporan keuangan yang tidak tepat waktu dalam penyampainnya dapat dikatan tidak relevan jika digunakan dalam pengambilan

keputusan. Keterlambatan dalam

penyampaian laporan auditan ini disebut audit report lag. Ahmad dan Kamarudin (2002) menyatakan bahwa "Audit report lag is the length of time from a company's fiscal year end to the date of the auditor's report" Hal ini diatur dengan Peraturan Bapepam Nomor X.K.2: Laporan keuangan tahunan wajib disampaikan kepada Bapepam dan LK dan diumumkan kepada masyarakat paling lambat pada akhir bulan ketiga setelah tanggal laporan keuangantahunan.

Fenomena audit repot lag ini dapat dilihat dari data BEI, pada tahun 2018 terdapat sebanyak 10 perusahaan yang terlambat dalam menyampaikan laporanauditannya. Dengan demikian, ketepatan waktu dalam penyampaian laporankeuangan merupakan hal yang krusial karena berhubungan dengan tingkat relevansi yang didapatkan publik dalam pengambilan keputusan yang didasarkan pada laporan keuangan.
Pekerjaan
auditor
adalah
untuk

memberikaninformasiyangbermanfaat,oleh sebab itu ketika laporan auditan mengalami keterlambatan maka akan mengurangi nilai guna dari laporan keuangan yang disajikan. Oleh karena itu, penting untuk diidentifikasi dan dilihat lebih dalam mengenai beberapa faktor yang berhubungan terhadap terjadinya audit report lag. Dengan demikian perlu dikaji apakah beberapa faktor tersebut berpengaruh secara signifikan terhadap terjadinya audit report lag. Hal ini menjadi penting karena fenomena audit report lag dapat menurunkan ketertarikan klien dan memengaruhi reputasi terhadap auditor dan Kantor Akuntan Publik di mana auditor bekerja.

Oleh sebab itu, peneliti tertarik untuk melihat seberapa besar pengaruhpengalaman auditor, time budget pressure, dan ukuran KAP terhadap audit reportlag.

\section{Pengalaman Auditor}

Arens et al (2014:20) menjelaskan bahwa pengalaman auditor menunjukkan sejauh mana penguasaan seseorang terhadap bidang pekerjaan yang selama iniditekuninya. Pada umumnya pengalaman kerja diukur dengan melihat seberapa lama waktu yang dihabiskan tenaga kerja pada suatu bidang pekerjaan tertentu. Pengalamanterdapat tiga indikator yaitu : lamanya menjadi auditor, frekuensi pekerjaan pemeriksaan,danpelatihanyangtelahdiikuti (Arens et $\mathrm{al}, 2014: 20)$. 


\section{Time BudgetPressure}

Alderman et al (1990:37) dalam Dwimilten dan Riduwan (2015) menjelaskan time budget pressure sebagai berikut:

"Suatu bagian dari perencanaan yang digunakan auditor yang menetapkan panduan dalam satuan waktu jam untuk setiap seksi dari audit. Jumlah jam harus dialokasikan dengan persiapan skedul kerja yang menunjukkan siapa yang melaksanakan serta apa dan berapa lama hal tersebut dilakukan. Kemudian total jam tersebut dianggarkan pada kategori utamadiprosedurauditdandisusundalam bentuk skedulmingguan."

Lebih lanjut, Coram (2004:2) menjelaskan bahwa: "Time budget pressure is considered to be a chronic and pervasive type of pressure faced by professional accountant."

Dengan demikian dapat disimpulkan bahwa Time budget pressure merupakan sebuah tuntutan kerja di mana auditor diharuskan untuk melakukan efisiensi terhadap anggaran waktu yang tersedia. Penerapan time budget yangtepat berdampak pada hasil kinerja termasuk adanya efisiensi dalam penjadwalan staff dan sebagai panduan dalam melakukan tugasaudit.

\section{Ukuran Kantor Akuntan Publik}

Menurut Undang-Undang No. 5 tahun 2011 Kantor Akuntan Publik merupakan badan usaha yang berbentuk perseorangan; persekutuan perdata, firma atau bentuk usaha lain yang sesuai dengankarakteristik profesi Akuntan Publik, yang diatur dalam Undang Undang. Sedangkan menurut Arens, Elder \& Beasly (2015), kantor akuntan publik adalah sebuah organisasi yang bergerak dibidang jasa. Jasa yang diberikan dapat berupa jasa audit kepatuhan (compliance audit), audit operasional dan audit laporan keuangan. Selain itu kantor akuntan publik juga memberikan jasa pajak dan konsultasi.

\section{Audit Report Lag}

Penyampaian laporan keuangan tahunan auditan menurut peraturan Bapepam nomor X.K.2 Laporan keuangan Tahunan wajib diampaikan paling lambat pada akhir bulan ketiga setelah tanggal laporan keuangan tahunan. Sehingga lamanya waktu dalam menyelesaikan laporan auditan tersebut berpengaruh terhadap ketepatan waktu penyampaian laporan keuangan tersebut. Dengan demikian, Ahmad dan Kamarudin (2002) menjelaskan bahwa "Audit report lag is the length of time from a company's fiscal year end to the date of the auditor's report".

\section{METODE}

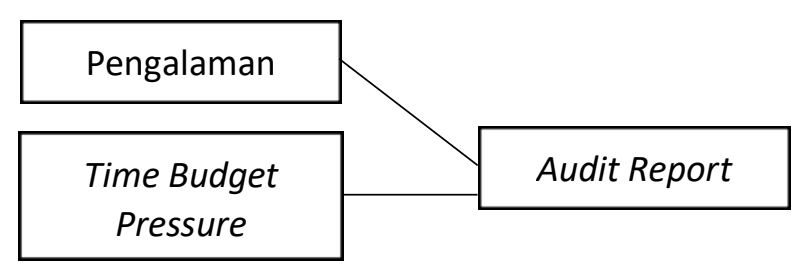

\section{Ukuran KAP}

$\mathrm{Y}=\mathrm{a}+\mathrm{b} 1 \mathrm{X} 1+\mathrm{b} 2 \mathrm{X} 2+\mathrm{b} 3 \mathrm{X} 3+\mathrm{e}$

Keterangan:

Y

$=$ Audit Report Lag

$\mathrm{X} 1=$ PengalamanAuditor

$\mathrm{X} 2=$ Time Budget Pressure

$\mathrm{X} 3=$ UkuranKAP

$\mathrm{a} \quad=$ konstanta $\mathrm{b} 1, \mathrm{~b} 2, \mathrm{~b} 3=$ koefisienregresi

$\mathrm{e}=$ error term (Faktor lain sebagai pengaruh yang tidak diteliti oleh peneliti)

\section{Jenis dan Sumber Data}

Penelitian ini menggunakan data kuantitatif. Sumber data merupakan data primer yang diperoleh melalui kuisioner.

\section{Teknik Sampling}

Teknik sampling yang digunakan adalah purposive sampling dengan sample sebanyak 29 responden yang bekerja sebagai auditor di KAP di Surabaya.

\section{Teknik Analisis Data}

Metode analisis yang digunakan dalam penelitin ini adalah regresi linear sederhana.

Tahap-tahap analisis data:

-Uji Validitas

-Uji Reabilitas

-Uji Normalitas

-Uji Multikolonieritas

-Uji Heteroskedasitas

-Uji Regresi Linear Sederhana

\section{HASIL DAN PEMBAHASAN}

\section{Uji Validitas}

\begin{tabular}{|c|c|c|}
\hline Variabel X1 & Sig & Keterangan \\
\hline X1.1 & 0,510 & Valid \\
\hline X1.2 & 0,540 & Valid \\
\hline X1.3 & 0,575 & Valid \\
\hline X1.4 & 0,551 & Valid \\
\hline X1.5 & 0,683 & Valid \\
\hline X1.6 & 0,599 & Valid \\
\hline X1.7 & 0,467 & Valid \\
\hline X1.8 & 0,655 & Valid \\
\hline
\end{tabular}

\begin{tabular}{|c|c|c|}
\hline Variabel X2 & Sig & Keterangan \\
\hline X2.1 & 0,549 & Valid \\
\hline X2.2 & 0,576 & Valid \\
\hline X2.3 & 0,701 & Valid \\
\hline
\end{tabular}


Dewi Sutjahyani, Pengaruh Pengalaman Auditor, Time Budget Pressure dan Ukuran Kantor Akuntan Publik Terhadap Audit Report LAG Pada Auditor Kantor Akuntan Publik Di Kota Surabaya

\begin{tabular}{|c|c|c|}
\hline X2.4 & 0,769 & Valid \\
\hline X2.5 & 0,588 & Valid \\
\hline X2.6 & 0,676 & Valid \\
\hline X2.7 & 0,542 & Valid \\
\hline
\end{tabular}

\begin{tabular}{|c|c|c|}
\hline Variabel X3 & Sig & Keterangan \\
\hline X3.1 & - & Tidak Valid \\
\hline X3.2 & 0,591 & Valid \\
\hline X3.3 & 0,084 & Tidak Valid \\
\hline X3.4 & 0,855 & Valid \\
\hline X3.5 & 0,798 & Valid \\
\hline
\end{tabular}

Dari hasil uji validitas diketahui bahwa dalam pertanyaan variabel X3 terdapat dua pertanyaan tidak valid sehingga harus di-drop yaitu X3.1 dan X3.3

\begin{tabular}{|c|c|c|}
\hline Variabel Y & Sig & Keterangan \\
\hline Y1.1 & 0,657 & Valid \\
\hline Y1.2 & 0,807 & Valid \\
\hline Y1.3 & 0,813 & Valid \\
\hline Y1.4 & 0,658 & Valid \\
\hline
\end{tabular}

\section{Uji Reabilitas}

\begin{tabular}{|l|l|l|}
\hline Variabel & $\begin{array}{l}\text { Cronbach } \\
\text { Alpha }\end{array}$ & Keterangan \\
\hline $\begin{array}{l}\text { Pengalaman } \\
\text { Auditor }\end{array}$ & 0,679 & Reliabel \\
\hline $\begin{array}{l}\text { Time Budget } \\
\text { Pressure }\end{array}$ & 0,740 & Reliabel \\
\hline Ukuran KAP & 0,637 & \\
\hline Audit Report Lag & 0,718 & Reliabel \\
\hline
\end{tabular}

Uji Normalitas

One-Sample Kolmogorov-Smirnov Test

\begin{tabular}{|ll|r|}
\hline & & $\begin{array}{l}\text { nstandardize } \\
\text { d Residual }\end{array}$ \\
\hline N & & 28 \\
Normal Parameters & a,b & Mean \\
& Std. & .0000000 \\
& Deviation & 1.82405182 \\
Most Extreme & Absolute & .147 \\
Differences & Positive & .147 \\
& Negative & -.096 \\
Test Statistic & .147 \\
Asymp. Sig. (2-tailed) & & $.126 \mathrm{C}$ \\
\hline
\end{tabular}
a. Test distribution isNormal.
b. Calculated from data.
c. Lilliefors SignificanceCorrection

Uji normalitas menunjukkan bahwa sampel penelitian tersebar mengikuti distribusi normal di mana $\alpha$ di atas 0,05 .

\section{Uji Multikolonieritas}

\section{Coefficients $\mathbf{a}^{\mathrm{a}}$}

Pengujian Hipotesis Hasil Uji Fit

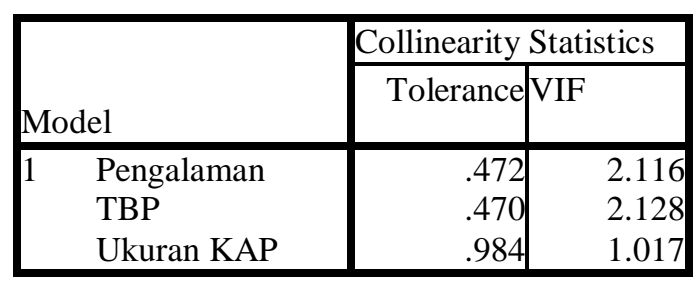

\section{ANOVA}

\begin{tabular}{|rl|r|c|c|}
\hline & \multicolumn{1}{c|}{$\mathbf{a}$} \\
& $\begin{array}{r}\text { Sum of } \\
\text { Squares }\end{array}$ & & \\
Model & & $\mathrm{F}$ & \\
\hline $1 \quad$ Regression & 65.467 & 6.251 & $.003^{\mathrm{b}}$ \\
& Residual & 83.783 & & \\
& Total & 149.250 & & \\
\hline
\end{tabular}

a. Dependent Variable:ARL

Hasil Uji Multikolonieritas menunjukkan bahwa nilai VIF $<10$ atau nilaitolerance $>0,1$ berarti bahwa tidak terjadi multikolonieritas dalam penelitian ini.

\section{Uji Heteroskedasitas}

Coefficients $\mathbf{a}$

\begin{tabular}{|c|c|}
\hline Model & Sig. \\
\hline (Constant) & .325 \\
\hline Ln_X1 & .560 \\
\hline Ln_X2 & 211 \\
\hline Ln_X3 & .052 \\
\hline
\end{tabular}

\begin{tabular}{|c|c|c|}
\hline Model & Sig. & Keterangan \\
\hline \begin{tabular}{|l}
1 \\
(Constant) \\
Pengalaman \\
Time Budget Pressure \\
Ukuran KAP
\end{tabular} & $\begin{array}{l}.182 \\
.310 \\
.201 \\
.020\end{array}$ & $\begin{array}{r}\text { Ditolak } \\
\text { Ditolak } \\
\text { Diterima }\end{array}$ \\
\hline
\end{tabular}

Jika nilai signifikansi lebih besar dari $0,05(\alpha)$ maka hipotesis ditolak, jika signifikansi lebih kecil dari $0,05(\alpha)$ maka hipotesisditerima.

Dengan demikian dapat diketahui bahwa hasil pengujian hipotesisadalah:

- Ha diterima berarti bahwa pengalaman auditor, time budget pressure, dan ukuran KAP berpengaruh secara simultan terhadap Audit Repor Lag.

- H1 ditolak berarti bahwa pengalaman auditor tidak berpengaruhsecara signifikan terhadap Audit Repor Lag.

- H2 ditolak berarti bahwa time budget pressure tidak berpengaruh secara signifikan terhadap Audit Repor Lag.

- H3 diterima berarti bahwa ukuran KAP berpengaruh secara signifikan terhadap Audit ReporLag.

\section{Pengaruh Pengalaman Auditor terhadap Audit Report Lag}

Hipotesis 1 dalam penelitian ini ditolak, hal ini 
Dewi Sutjahyani, Pengaruh Pengalaman Auditor, Time Budget Pressure dan Ukuran Kantor Akuntan Publik Terhadap Audit Report LAG Pada Auditor Kantor Akuntan Publik Di Kota Surabaya

berarti bahwa pengalaman auditor tidak berpengaruh secara signifikan terhadap Audit ReportLag.Pengalamandalamhalinidiukurdari lama kerja dan banyaknya tugas pemeriksaan. Variabel pengalaman tidak berpengaruh secara signifikan karena kualitas audit tidak ditentukan oleh lama kerja dan banyaknya tugasaudit.

\section{Pengaruh Time Budget Pressure terhadap Audit Report Lag}

Hipotesis 2 yaitu time budget pressure berpengaruh terhadap audit report lag diolak. Tekanan anggaran waktu merupakan hal yang vital dalam proses penyelesaian laporan audit. Dalam hal ini tekanan anggaran waktu tidak berpengaruhsecarasignifikankarenatimebudgetpressure ditentukan pada saat melakukan planning dalam menentukan tugas audit namun pelaksanaan audit dapat berbeda dipengaruhi oleh situasi yang ada. Misalnya pada saat pandemi, situasi yang tidak dapat dikontrol menyebabkan adanya kelonggaran dalam penyelesaian laporan auditan. Sehingga tekanan anggaran waktu yang ada harus diseuaikan.

\section{Pengaruh Ukuran Kantor Akuntan Publik terhadap Audit Report Lag}

Hipotesis3dalampenelitianiniditerima, hal ini karena ukuran KAP pada dasarnya menentukan tingkat efesiensi dan efektifitas tugas setiap auditor. Dalam KAP menengah dan besar biasanya terdapat sistem yang terstruktur dan kematangan dalam proses perencanaan audit hingga pelaksaaan audit. Hal ini dikarenakan Kantor Akuntan Publik besar biasanya berusaha memperthankan kualitas dan reputasi untuk tetap menarik minat kliennya. Hal ini didukung oleh penelitian yang dilakukan oleh Elen P. dan Anggraeni N.S pada tahun 2015 yang menyatakan bahwa besarnya ukuran KAP dapat digunakan sebagai alat ukur kualitas jasa audit yang diberikan. Hal ini karena dalam KAP besar tingkat profesionalitas auditor dapat dipacu dengan standar tertentu, kemudian melihat juga teknologi yang digunakan serta jumlah auditor yang bekerja pada KAP. Besarnya jumlah auditor di KAP dapat menunjukkan diversivikasi dan kemudahan dalam aspek problem solving karena jumlah auditor yang bepengalaman akan semakin banyak dan mampu membantu auditor junior.Ha lini berarti bahwa circle atau lingkungan dalam KAP mampu memacu auditor dalam melaksanakan tugas audit tepat waktu. Faktor lain yaitu biasannya dalam KAP besar terdapat company culture yang memaksa auditor untuk tetap fit in sehingga dapat bekerja sesuai dengan standar yang ditentukan.

\section{SIMPULAN}

Terdapat pengaruh signifikan ukuran KAP terhadap audit report lag. Hal ini dibuktikan dengan nilai signifikansi sebesar $0,020<(\alpha) 0,05$.

\section{DAFTAR PUSTAKA}

Arens, Alvin A. Randal J. Elder dan Mark S. Beasley. 2014. Auditing dan Jasa Assurance (terjemahan). Edisi kelimabelas. Jakarta: Erlangga.

Ahmad,R.A.R., dan K.A Kamarudin. 2003. Audit Delay and The Timeliness of Corporate Reporting: Malaysian Evidence. Proceeding Hawaii International Conference on Business. Hawaii

Bonner, S.E. 1994. A Model of the effects of audit task complexity. Accounting, Organisations and Society, 19, $213-234$.

Boynton, W.C., Johnson dan Kell. 2003. "Modern Auditing". Edisi Ketujuh, Jilid 1. Jakarta : Erlangga. Christiawan. 2002. Identifikasi Karakteristik-Karakteristik Audit Profesi Akuntan Publik di Indonesia. Jurnal Riset Akuntansi dan Auditing 2 (1) Januari.

Dwimilten, Eunike dan Akhmad Riduwan. 2015. Faktorfaktor yang Mempengaruhi Kualitas Audit. Jurnal Ilmu \& Riset Akuntansi. Vol. 4 No. 4 (2015)

Coram, Paul., Juliana NG, David. R. Woodliff. 2004. "The Effects of Time Budget Pressure and the Risk of Error on Auditor Performance."

Pambudy, A. P., \& Syairozi, M. I. (2019). Analisis Peran Belanja Modal dan Investasi Swasta Terhadap Pertumbuhan Ekonomi Serta Dampaknya Pada Kesejahteraan Masyarakat. Jurnal Ekonomi dan Bisnis, 20(1), 26-39.

Peraturan Nomor. X.K.2, Lampiran Keputusan Ketua BAPEPAM dan LK Nomor. KEP- 346/BL/2011

Prabowo, P. A. (2020). ANALISA PERILAKU KONSUMEN JASA KATERING UNTUK KEPERLUAN PESTA DI SURABAYA. JURNAL EKBIS: ANALISIS, PREDIKSI DAN INFORMASI, 21(1), 69-90.

Syairozi, M. (2015). Pengaruh Faktor Eksternal (Inflasi, Bunga) Dan Faktor Internal (Bagi Hasil, Jumlah Bank) Terhadap Deposito Mudharabah Pada Perbankan Syariah Di Indonesia (Doctoral dissertation, Universitas Brawijaya).

Syairozi, M. I. (2019). KETERKAITAN VARIASI PRODUK DAN TENAGA KERJA TERHADAP PENINGKATAN LABA BENGKEL AHAS PANDAAN.

TriDianaWahyu.(2014).PengaruhUkuranPerusahaan,Pro fitabilitas,Solvabilitas,JenisIndustri dan Ukuran Kantor Akuntan Publik terhadap Audit Delay (Studi Kasus padaPerusahaan Indeks LQ 45 yang Terdaftar di Bursa Efek Indonesia Tahun 20102013). Skripsi. Yogyakarta: Universitas NegeriYogyakarta.

Undang-Undang Republik Indonesia Nomor 5 Tahun 2011 tentang "Akuntan Publik".

Widiastoeti, H., \& Sari, C. A. E. (2020). PENERAPAN

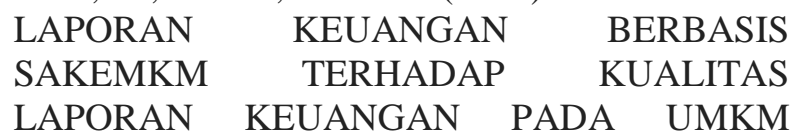


Dewi Sutjahyani, Pengaruh Pengalaman Auditor, Time Budget Pressure dan Ukuran Kantor Akuntan Publik Terhadap Audit Report LAG Pada Auditor Kantor Akuntan Publik Di Kota Surabaya

KAMPUNG KUE DI RUNGKUT

SURABAYA. JURNAL EKBIS: ANALISIS,

PREDIKSI DAN INFORMASI, 21(1), 1-15. 